\title{
DETECTION OF RIDGE GOURD (Luffa acutangula) FRUIT QUALITY DURING STORAGE USING NEAR-INFRARED SPECTROMETER
}

\author{
Kusumiyati ${ }^{1}$, Syariful Mubarok ${ }^{1}$, Jajang Sauman Hamdani ${ }^{1}$, Farida ${ }^{1}$, Wawan Sutari ${ }^{1}$, Yuda Hadiwijaya ${ }^{2}$, \\ Ine Elisa Putri ${ }^{2}$ \\ ${ }^{1}$ Lecturer of Agrotechnology Studies Program of Agriculture Faculty of Padjadjaran University \\ ${ }^{2}$ Alumni of Agrotechnology Studies Program of Agriculture Faculty of Padjadjaran University \\ E-mail : kusumiyati@gmail.com
}

\begin{abstract}
Fruit quality detection using near-infraread spectrometer is fast and it does not damage the fruit, hence the fruit is still marketable. The aim of this research focused on analyzing quality component of ridge gourd during storage using near-infrared spectrometer. The research was conducted on March to July 2017 at the Laboratory Plant Production Technology of Horticulture Division of Agriculture Faculty of Padjadjaran University, Jatinangor. Ridge gourds were harvested at the same maturity stage from the orchad, then stored at 5 and 10 days. The method used in this research was multivariate data analysis using Unscrambler software (version 7.51, CAMO, Oslo, Norway). The data acquisition was taken using portable near-infrared (NIR) spectrometer (NirVana AG410, Integrated Spectronics Pty, Ltd, Australia) with wavelength range of 600-1100 nm and stored as absorbance spectra and pretreated by secondderivatives spectra using ISIS software (Integrated Spectronics Pty, Ltd, Australia). The results showed that non-destrucive method using near-infrared spectrometer was able to measure ridge gourd fruit quality component such as, total dissolved solid, moisture content, firmness and color values.
\end{abstract}

Keywords : calibration, loofah, validation

\section{INTRODUCTION}

Ridge gourd (Luffa acutangula) is a cucurbitaceous vegetable crop grown in some tropical countries of asia including Indonesia. Indonesia is a country that has fertile land which various types of plants grow well, especially horticultural crops such as vegetables and fruits. Food demand is expected to increase due to the population growth. Moreover, some crops also have good benefits for health.

Quality of fruit is generally determined only based on visual estimation, such as size, skin color, and weight. Besides, it requires laboratory analysis to obtain the information about internal quality. In conventional analysis, the samples have to be destructed and homogenized. Complex procedures and some hazardous chemicals are also needed. This method is considered to be time and cost consuming, requiring materials and manual work (Gómez et al., 2006; Nicolaï et al., 2007).

Since 1990s, near infrared spectroscopy has been used to predict fruit quality (Kawano, 1998). This technique is time and labor reducing alternatives. Near infrared spectroscopy (NIRS) provides a rapid, accurate, and enviromental friendly method for measurement fresh commodities (Blanco and Villarroya, 2002). Spectrometer records spectrum consist of physical and chemical information of radiated samples such as soluble solids content (SSC), firmness, and internal defect (McGlone et al., 2002; Sun et al., 2010). This technique has been previously used to predict fruit quality of prune (Slaughter et al., 2003), mango (Saranwong et al., 2004), apricot (Chen et al., 2006), apple (Lieu et al., 2007; Bobelyn et al., 2010), Jujube (Wang et al., 2011), and Fuji apple (Liu and Ying, 2005) with reliable accuracy. Near-infra red spectrometer is also used for detecting some fruit-vegetable commodities, such as tomato (Kusumiyati et al., 2007, Kusumiyati et al., 2008), bitter gourd (Kusumiyati et al., 2008), and cucumber.Once separated from the plant, as living organism fruits keep on respiration until senescence (Ranganna, 2008). The harvested fruit can not obtain water and nutrient from the plant anymore for it's ripening processes. The respiration determines potential shelf life (Varoquaux and Ozdemir, 2005). Therefore, this work aims to focus on analyzing quality component of ridge gourd during storage using near-infrared spectrometer. 


\section{MATERIALS AND METHODS}

Ridge gourds were harvested at the same maturity stage from the field experiment, then stored indoors at room temperature. Then all the fruits that have been harvested, one-third part are directly tested (Ho), another third stored for five days then tested on the fifth day $\left(\mathrm{H}_{5}\right)$, then other third stored for ten days and tested on day 10 $\left(\mathrm{H}_{10}\right)$. The ridge gourd samples used in this study were 300 each for storage treatment. Each time the test is conducted on 50 samples. Prior to test the fruit was treated with pre-cooling for 2 hours.

The tools used in this research were tension gauge (AND Model AD-4932A-50 N, Taiwan) was used to the center of the fruit until punture to measure fruit firmness, in addition Texture analyzer (TA XT Express Enhanced Stable Micro system, Germany) is also used to measure the value of fruit firmness.

Measurement of moisture content by gravimetric method, Sliced fruit and then put in cup aluminum foil, dried in oven (Jouan EB.100, Germany) at $80^{\circ} \mathrm{C}$ until its weight constant. Before and after inserted into the oven, weighed to determine the fresh water content of the fruit using the digital scales (ACIS, MN Series). Measurements of water content of the fruit were measured at the top, middle and bottom of the ridge gourd fruit.

The color of fruit is measured by using chroma meter to obtained the value of $L^{*}, a^{*}, b^{*}$. The $L^{*}$ value describes the brightness of the color, where 0 is for black and 100 white. The value of a* indicates the type of green - red, where negative $a^{*}$ is green, whereas positive $a^{*}$ is a red color. The $b^{*}$ denotes the blue-yellow type, where the negative $b^{*}$ is blue, while the positive $b^{*}$ is yellow. Fruit color measurements were taken from two different sides of the fruit, in each side measured at the top, middle and bottom of the ridge gourd fruit. The upper part is the part attached to the stem of the fruit.

The total soluble solids measurements used a refractrometer (PR1 Atago, Japan) taken from extract of the top, middle and bottom of the ridge gourd fruit. All of the measurements were done at laboratory.

The method used in this research was multivariate data analysis using Unscrambler software (version 7.51, CAMO, Oslo, Norway). The data acquisition was taken using portable near-infrared (NIR) spectrometer (NirVana AG410, Integrated Spectronics Pty, Ltd, Australia) with wavelength range of 600-1100 nm and stored as absorbance spectra and pretreated by second-derivatives spectra using ISIS software (Integrated Spectronics Pty, Ltd, Australia).

\section{RESULTS AND DISCUSSION}

\section{A. Destructive Data Analysis on Ridge Gourd}

Measurement of ridge gourd composition by destructive method is used as reference data in the development of calibration model. These data determine the success of estimating value of quality components using NIR. All measurement processes will surely produce errors, including destructive measurements. Therefore, to reduce the occurrence of errors it is done special handling to the sample. Ridge gourd sample that has been radiated by NIR Spectrometer, then as soon as possible should be directly analyzed of it's chemical composition in the laboratory. This is needed to prevent the changes of chemical characteristics of ridge gourd. Data analysis of 300 ridge gourd samples can be seen on Table 1 .

Ridge gourd fruit after harvest continues to respire resulting in some physical changes and chemical content in ridge gourd. The most common changes during ripening are color change, texture and total dissolved solids (O'brien et al, 1983 in Alfansuri, 2012). Ridge gourd fruit samples used in this research were taken from the same maturity stage, then stored for 0,5 and 10 days.

The average value of ridge gourd moisture content by destructive method is $90.89 \%$. The value of moisture content affects the durability and freshness of ridge gourd fruit during storage. The standard deviation for moisture content is 0,02314 . This value indicates that the water content dataset is considerable diverse.

Firmness is form of physical changes in the maturity stage of ridge gourd fruit. Immature fruit is considered to have higher firmness value, in the other hand full mature fruit is considered to have lower firmness value.

Total dissolved solids (TDS) is soluble solids contained on ridge gourd as measured by using refractometer. The amount of measured soluble solid content on the ridge gourd is a measurable portion of TDS. The average value of TDS on 300 ridge gourd samples were 3.52\% Brix. TDS measurements were performed on the upper, middle and lower of ridge gourd samples so as to obtain the value of TDS thoroughly.

Color assessment by destructive method is determined by measuring the amount of reflected light from the surface of ridge gourd fruit. Color notation system is characterized by 5 parameters such as $\mathrm{L}^{*}, \mathrm{a}^{*}, \mathrm{~b}^{*},{ }^{0}$ hue and chroma. In the table can be seen that average value of $\mathrm{L}^{*}$ is 41,84 , the higher value of $\mathrm{L}^{*}$ means the color of ridge gourd is brighter. Average value of $\mathrm{a}^{*}$ is $-9,71$ indicating that the color of fruit is getting green. Then the average value of $b^{*}$ is 17,91 which states that the color of ridge gourd fruit leads to the yellow color due to some samples of ridge gourd stored for 5 and 10 days. Average of ${ }^{0}$ hue value is $-60,93$ which indicates greed ridge gourds lead to yellow. While the average value of chroma is 20,44 which means the level of color content from immature to full mature. The higher the value of chroma indicates the color of ridge gourd fruit is getting matured.

Standard deviation (SD) describe the diversity of single set of data being analyzed. Largest statistical data variation is found in ${ }^{0}$ hue value as 4,84 and the lowest variation in total dissolved solids value as 0.52 . Maximum 
and minimum statistic data of 300 fruit samples show the high range. The table presented below is a summary of ridge gourd analysis result by destructive method.

Table 1. Statistic Data Analysis of 300 Ridge Gourd Samples By Destructive Method

\begin{tabular}{|c|c|c|c|c|c|}
\hline \multicolumn{2}{|c|}{ Composition } & Ave & SD & Min & Max \\
\hline \multicolumn{2}{|c|}{ Moisture Content } & 0,9089 & 0,023 & 0,729 & 0,998 \\
\hline \multicolumn{2}{|c|}{ Firmness (N) } & 16,205 & 3,855 & 4,11 & 35,58 \\
\hline \multicolumn{2}{|c|}{ TDS (\%) } & 3,5279 & 0,525 & 1,2 & 6,9 \\
\hline \multirow[t]{5}{*}{ Color } & $\mathrm{L}^{*}$ & 41,840 & 4,158 & 0,95 & 54,18 \\
\hline & $a^{*}$ & $-9,717$ & 1,579 & $-21,3$ & $-3,44$ \\
\hline & $\mathrm{b}^{*}$ & 17,915 & 3,966 & 4,73 & 30,02 \\
\hline & $\mathrm{Hue}^{0}$ & $-60,93$ & 4,844 & $-79,17$ & $-41,489$ \\
\hline & Chroma & 20,448 & 3,932 & 5,8486 & 33,929 \\
\hline
\end{tabular}

\section{B. Near-Infrared Data Analysis of Ridge Gourd}

Data analysis on moisture content, firmness, total dissolved solids and color were measured by reflectant data and NIR absorbance data using multivariate calibration method as partial least square (PLS). Partial least square (PLS) was developed by Herman Wold (1982). PLS was used to estimate a series of bound variables from a large number of independent variables, which has linear or nonlinear systematic structure, with or without missing data and high collinearity. PLS is a widely used bilinier modeling to connect physical properties and content of a material to its spectral data. This method establishes the estimation model from estimating a set of non-free and independent variables, thus forming a linear or non-linear systematic structure with or without missing data and can set aside the multi-cholinearity problem in the spectrum of reflectant and absorbant data (Lindblom, 2004 in Gabbie, 2011).

\section{Ridge Gourd Data}

Absorbance data is obtained from the process of absorption of ridge gourd fruit sample. Absorbance data is feasible to analyze thin-skinned commodities and directly attached to the pulp such as ridge gourd, sapodilla, squash, etc. The amount of samples used is 300 samples. The sample used for calibration phase are different from the sample used for the validation phase.

\section{Moisture Content Assessment}

At calibration phase the assessment of moisture content used 627 samples of reflectant data and 601 samples for validation phase with wavelength $312-1050 \mathrm{~nm}$. The calibration Fig. of moisture content is presented on Fig. 1. Data analysis of calibration and validation phase of moisture content assessment using reflectant data with PLS method is presented on Table 2 .

Table 2. Data analysis of calibration and validation phase of moisture content assessment based on absorbant data with partial least square method

\begin{tabular}{|c|c|c|c|c|c|c|c|}
\hline & $\mathrm{n}$ & $\mathrm{R}$ & Min & Max & Ave & SD & SE \\
\hline Calibration & 627 & 0,702 & $84 \%$ & $93 \%$ & $91 \%$ & 0.01883 & 0,01 \\
\hline Validation & 601 & 0,586 & $83 \%$ & $93 \%$ & $90 \%$ & 0.0166 & 0.10 \\
\hline
\end{tabular}

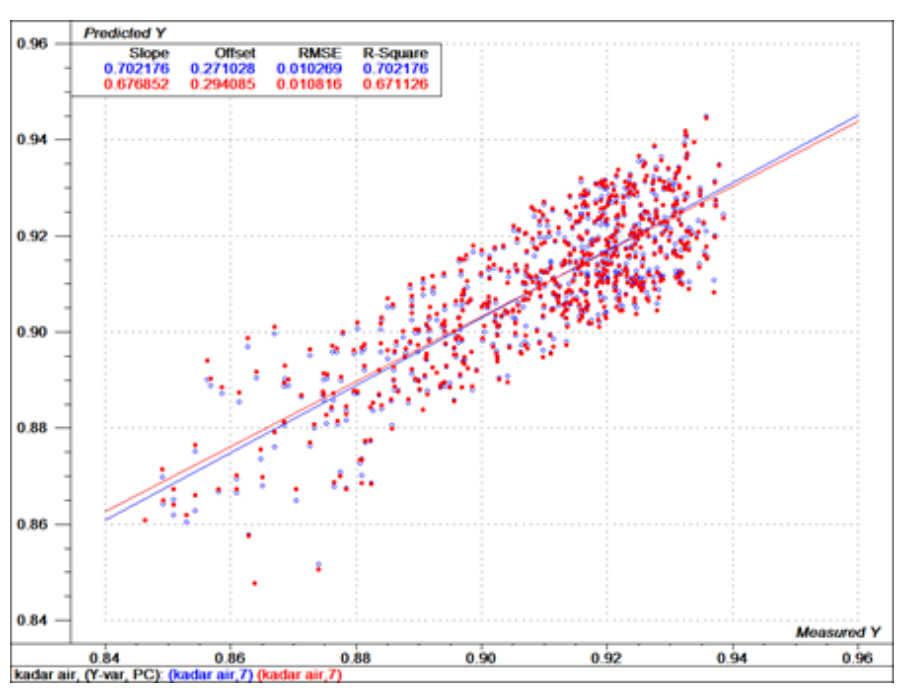

Fig. 1. Calibration of Moisture Content on Ridge Gourd 
Correlation coefficient (R) for assessment of moisture content value of ridge gourd is 0,70 means high (closed to 1). This shows that the NIR prediction is close to the measurement value by using destructive method. At the calibration phase, the standar error of calibration (SEC) is 0,01 . Considering the standard error value at calibration phase, it can be assumed that the calibration regression has been built well because the default error value near to zero (0). To analyze the accuracy of regression equation of calibration it is necessary to perform the validation phase.

The validation phase of moisture content assessment of ridge gourd fruit used different samples from calibration which 601 samples from NIR absorbance data and destructive method measurement. The level of accuracy in the validation phase based on the form and model of calibration largely determined by the standard error of prediction (SEP). Based on the result of the validation phase obtained, it can be examined that the standard error prediction (SEP) generated is 0,10. Standard error prediction is acceptable due to close to zero. The validation Fig. of moisture content is presented on Fig. 2. The combination of calibration and validation of moisture coontent is presented on Fig. 3.

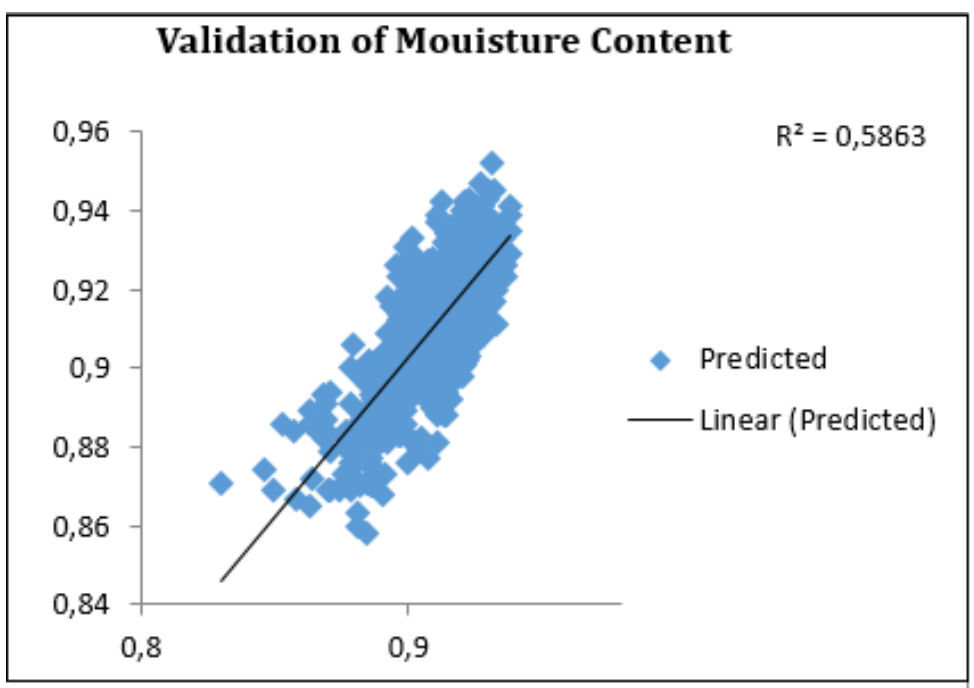

Fig. 2. Validation of Moisture Content on Ridge Gourd

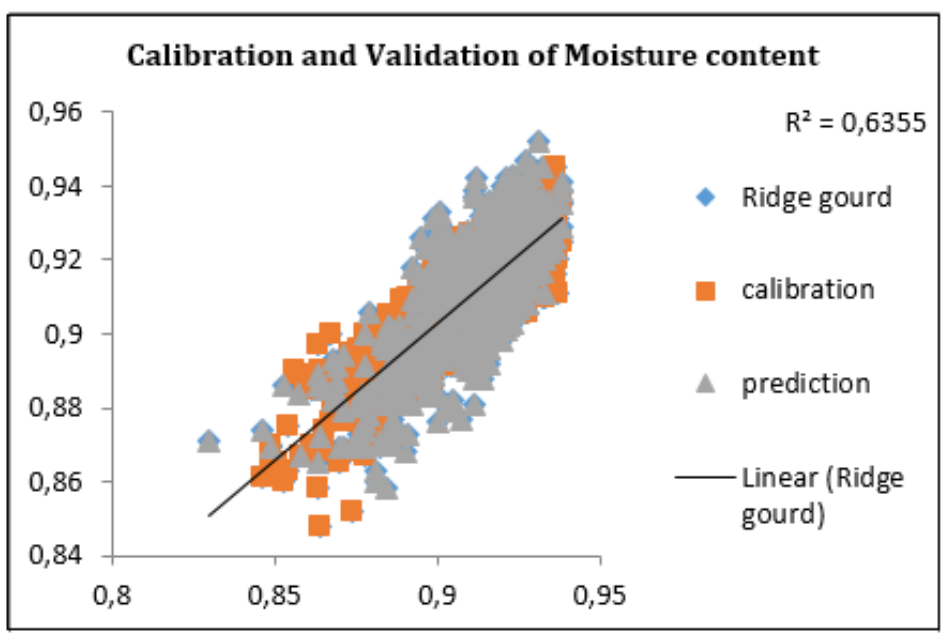

Fig. 3. Calibration and Prediction of Moisture Content on Ridge Gourd

\section{E. Firmness Assessment}

At calibration phase the assessment of firmness used 616 samples of reflectant data and 603 samples for validation phase with wavelength 312- $1050 \mathrm{~nm}$. Data analysis of calibration and validation phase of firmness assessment using reflectant data with PLS method is presented on Table 3.

Table 3. Data analysis of calibration and validation phase of firmness assessment based on absorbant data with partial least square method

\begin{tabular}{cccccccc}
\hline & $\mathrm{n}$ & $\mathrm{R}$ & Min & Max & Ave & SD & SE \\
\hline Calibration & 616 & 0,526 & 4.11 & 30.25 & 15.949 & 3.834 & 2,63 \\
Validation & 603 & 0,490 & 4.73 & 30.25 & 16.365 & 3.131 & 1,77 \\
\hline
\end{tabular}


Correlation coefficient (R) for firmness assessment of ridge gourd is 0,526 means high (closed to 1 ). This shows that the NIR prediction is close to the measurement value by using destructive method. The calibration Fig. of firmness is presented on Fig. 4.

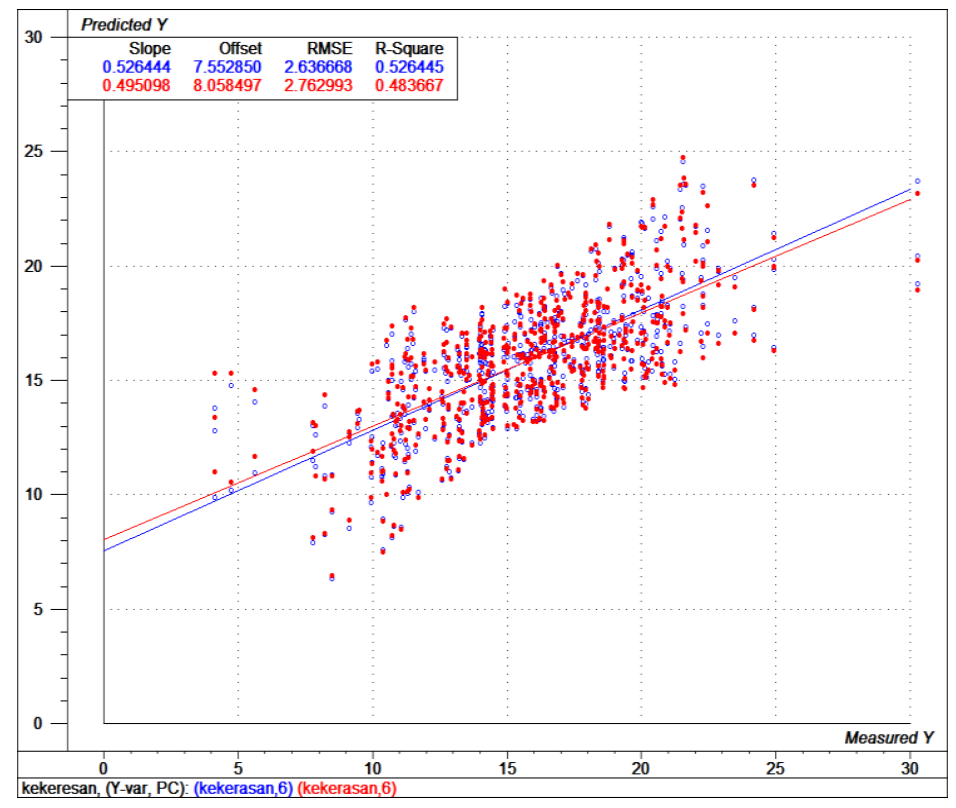

Fig. 4. Calibration of Firmness on Ridge Gourd

At calibration phase, the standard error of calibration (SEC) is $2.63 \%$. Considering the standard error values at the calibration phase, it can be assumed that the calibration regression that has been built is not good due to the default error value exceeds one (1). To analyze the accuracy of regression equation of calibration it is necessary to perform the validation phase.

The validation phase of firmness assessment of ridge gourd fruit used different samples from calibration which 603 samples from NIR absorbance data and destructive method mesurement. The level of accuracy in the validation phase based on the form and model of calibration largely determined by the standard error of prediction (SEP). Based on the result of the validation phase obtained, it can be examined that the standard error prediction (SEP) generated is 1,77. Standard error validation is not good because the value exceeds one (1). The validation Fig. of firmness is presented on Fig. 5. The combination of calibration and validation of firmness is presented on Fig. 6.

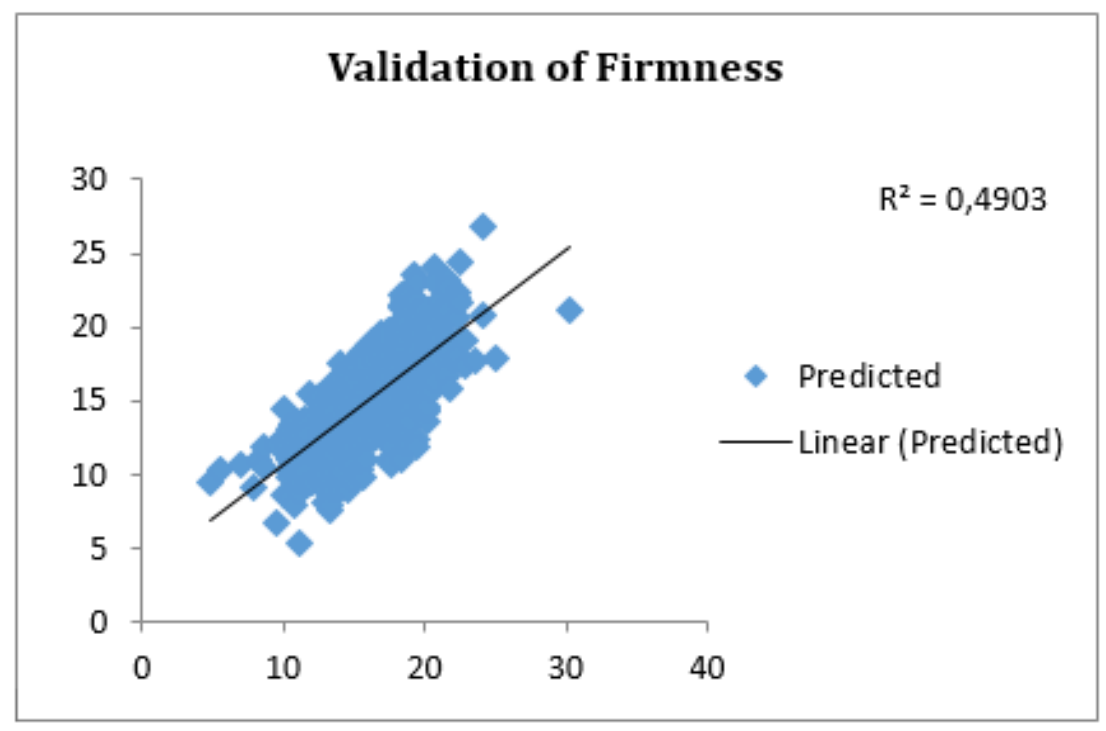

Fig. 5. Validation of Firmness on Ridge Gourd 


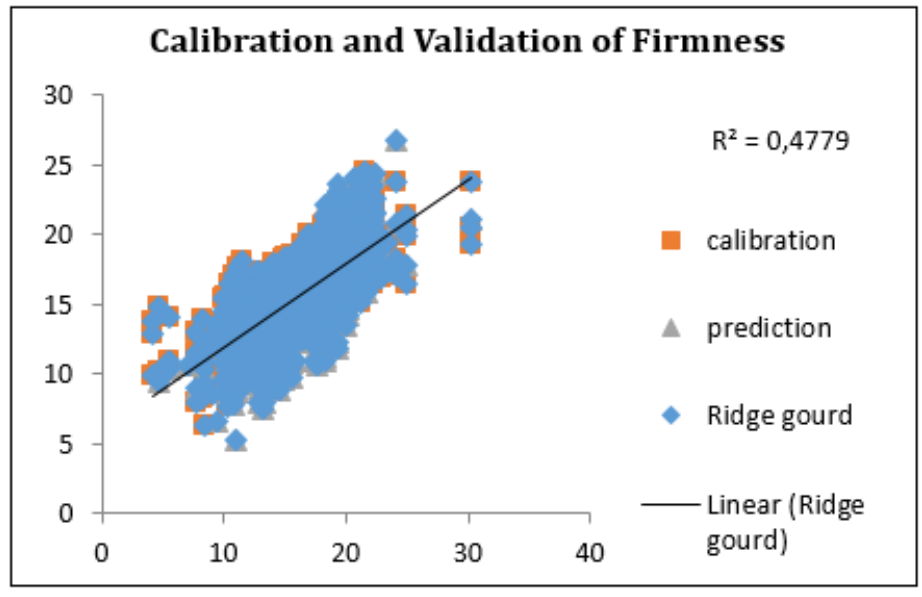

Fig. 6. Calibration and Validation of Firmness on Ridge Gourd

\section{F. Total Dissolved Solids Assessment}

At calibration phase the assessment of TDS used 610 samples of reflectant data and 615 samples for validation phase with wavelength 312- $1050 \mathrm{~nm}$. Data analysis of calibration and validation phase of TDS assessment using reflectant data with PLS method is presented on Table 4.

Table 4. Data analysis of calibration and validation phase of total dissolved solids assessment based on absorbant data with partial least square method

\begin{tabular}{cccccccc}
\hline & $\mathrm{n}$ & $\mathrm{R}$ & Min & Max & Ave & SD & SE \\
\hline Calibration & 610 & 0,484 & 1.2 & 6.9 & 3.520 & 0.643 & 0,46 \\
Validation & 615 & 0,450 & 2.3 & 5.5 & 3.479 & 0.395 & 0,82 \\
\hline
\end{tabular}

Correlation coefficient (R) for TDS assessment of ridge gourd is 0,48 means high (closed to 1). This shows that the NIR prediction is close to the measurement value by using destructive method. The calibration Fig. of TDS is presented on Fig. 7.

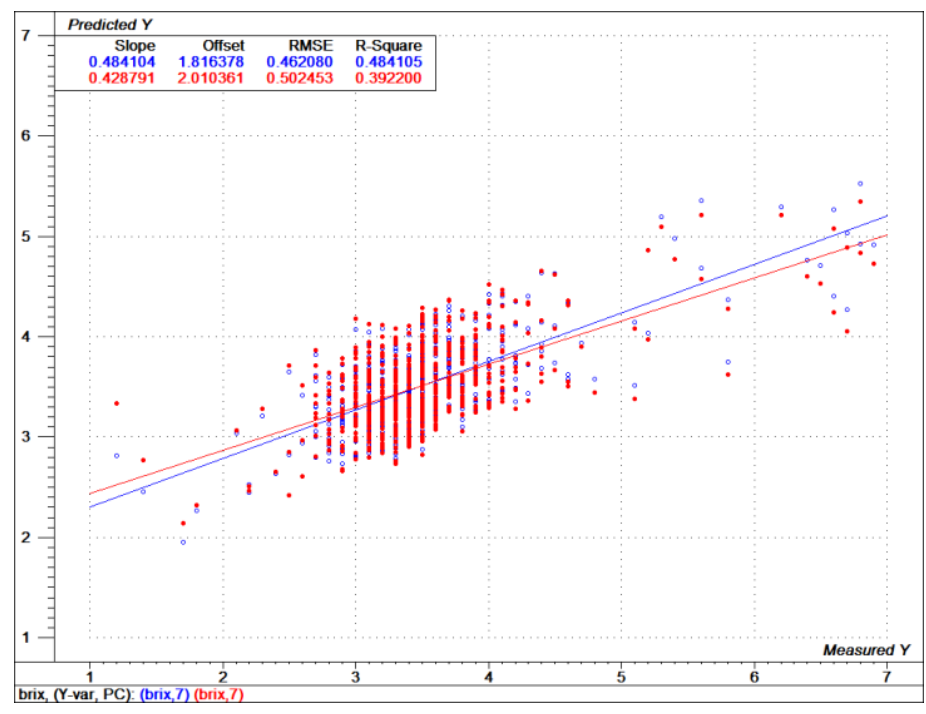

Fig. 7. Calibration of TDS on Ridge Gourd

At the calibration phase, the standar error of calibration (SEC) is 0,46 . Considering the standard error value at calibration phase, it can be assumed that the calibration regression has been built well because the default error value is close to zero (0). To analyze the accuracy of regression equation of calibration it is necessary to perform the validation phase.

The validation phase of TDS assessment of ridge gourd fruit used different samples from calibration which 615 samples from NIR absorbance data and destructive method mesurement. The level of accuracy in the validation phase based on the form and model of calibration largely determined by the standard error of prediction (SEP). Based on the result of the validation phase obtained, it can be examined that the standard error prediction (SEP) generated is 0,82 . Standard error prediction is acceptable due to close to zero. The validation Fig. of TDS is presented on Fig. 8. The combination of calibration and validation of TDS is presented on Fig. 9. 


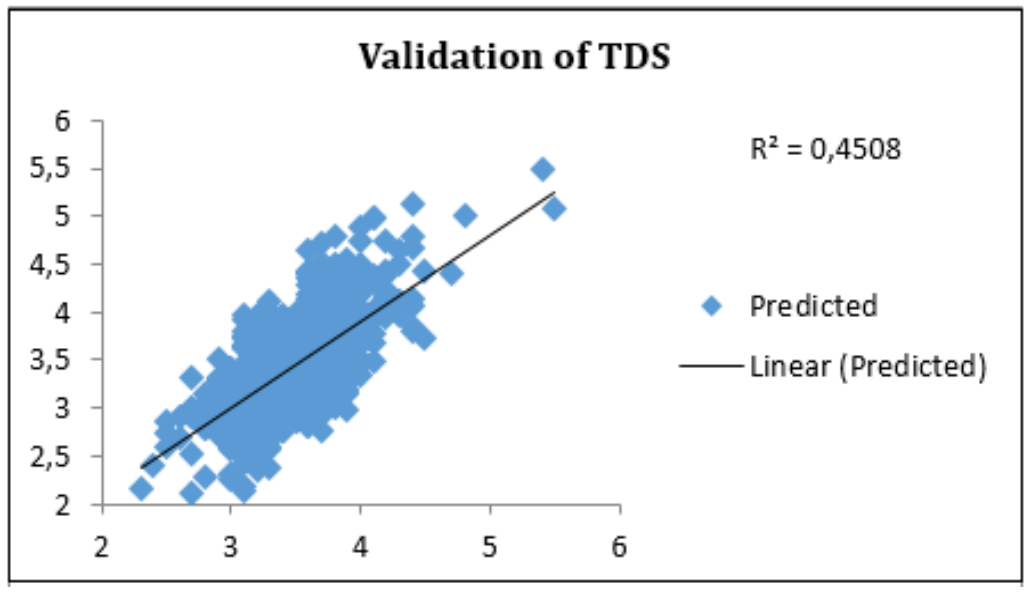

Fig. 8. Validation of TDS on Ridge Gourd

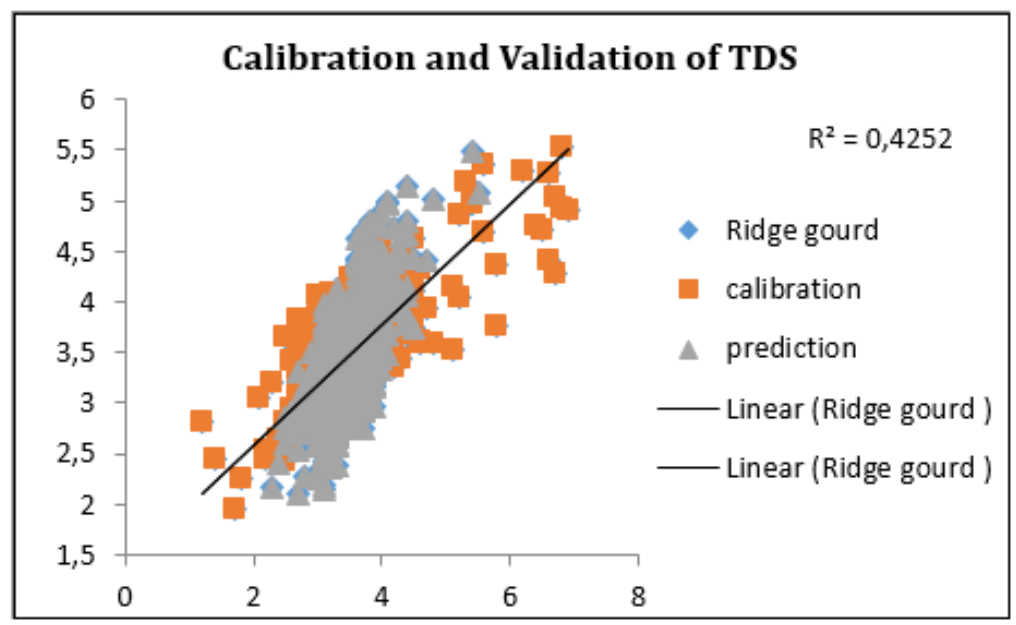

Fig. 9. Calibration and Validation of TDS on Ridge Gourd

\section{G. Color Assessment}

Color measurement is one of the methods used in assessing the appearance quality (visual ) of fresh horticultural products. Color measurements using numerical color codes are $\mathrm{L}^{*} \mathrm{a}^{*} \mathrm{~b}^{*}$ or often referred as "Hunter" notation. The $\mathrm{L}^{*}$ notation denotes reflected light that produces white, gray and black acromatic color (0: black, 100: white). Value of $\mathrm{a}^{*}$ denotes the gree red blended chromatic color with a+ from 0 to 100 for red and -a from 0 to 80 for green. Value of $b^{*}$ represents blue yellow blended chromatic color with $+b$ from 0 to +70 for the yellow and 0 to -70 for blue. According to Mohsein (1984), Munsell's method based on three Munsell notes: Hue ${ }^{0}$ (green, red, blue, yellow), Value (brightness or L or darkness to light/bright) and Chroma colors that move from light to dark).

At the calibration phase of color assessment including $\mathrm{L}^{*}, \mathrm{a}^{*}, \mathrm{~b}^{*}$. Hue $\mathrm{H}^{0}$ and Chroma used different reflectant data on each measurement for calibration and validation stages with wavelength 312-1050 nm. Data analysis of calibration and validation phase of color assessment using reflectant data with PLS method is presented on Table 5 .

Table 5. Data analysis of calibration and validation phase of color assessment based on absorbant data with partial least square method

\begin{tabular}{ccccccccc}
\hline & & $\mathrm{n}$ & $\mathrm{R}$ & $\mathrm{Min}$ & Max & Ave & SD & SE \\
\hline $\mathrm{L}^{*}$ & Cal & 600 & 0,80 & 28.1 & 52.0 & 42.21 & 3.733 & 1,66 \\
& Val & 612 & 0,77 & 32.3 & 50.9 & 42.06 & 3.338 & 1,33 \\
$\mathrm{a}^{*}$ & Cal & 627 & 0,62 & -14.2 & -4.34 & -9.86 & 1.471 & 0,90 \\
& Val & 600 & 0,57 & -13.5 & -5.41 & -9.86 & 1.354 & 1,12 \\
$\mathrm{~b}^{*}$ & Cal & 600 & 0,86 & 7.31 & 29.9 & 18.00 & 4.118 & 1,48 \\
& Val & 608 & 0,84 & 4.75 & 28.0 & 18.04 & 3.969 & 1.55 \\
Hue $^{0}$ & Cal & 615 & 0,86 & -72.9 & -48.7 & -60.7 & 4.493 & 1,67 \\
& Val & 618 & 0,83 & -75.3 & -49.6 & -60.4 & 4.150 & 1,38 \\
Chrom & Cal & 627 & 0,82 & 5.84 & 33.9 & 20.60 & 4.317 & 1,82 \\
$\mathrm{a}$ & Val & 620 & 0,81 & 8.90 & 30.8 & 20.50 & 3.821 & 1,73 \\
\hline
\end{tabular}


Correlation coefficient (R) for the color assessment of $\mathrm{L}^{*}, \mathrm{a}^{*}, \mathrm{~b}^{*}$. Hue $\mathrm{H}^{0}$ and Chroma values on ridge gourd are high (closed to 1). This shows that the NIR prediction is close to the measurement value by using destructive method. The calibration Fig. of $\mathrm{L}^{*}$ is presented on Fig. 10.

\section{H. L*Value}

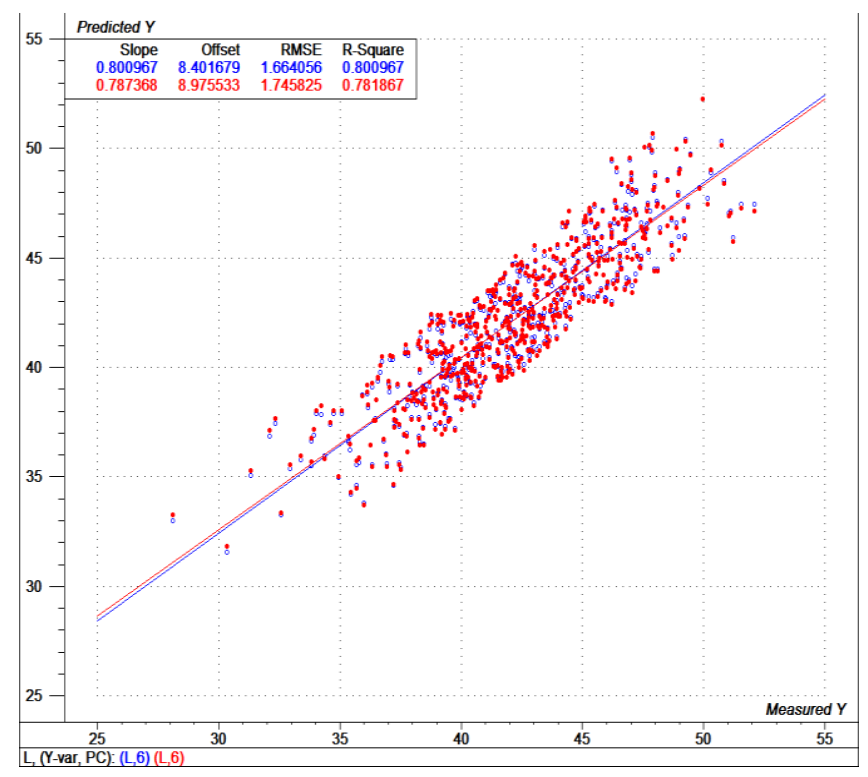

Fig. 10. Calibration of $\mathrm{L}^{*}$ on Ridge Gourd

At calibration phase, the standard error of calibration (SEC) is 1,66 considering the standard error values at the calibration phase, it can be assumed that the calibration regression that has been built is not good due to the default error value exceeds one (1). To analyze the accuracy of regression equation of calibration it is necessary to perform the validation phase.

The validation phase of $\mathrm{L}^{*}$ assessment of ridge gourd fruit used different samples from calibration which 612 samples from NIR absorbance data and destructive method mesurement. The level of accuracy in the validation phase based on the form and model of calibration largely determined by the standard error of prediction (SEP). Based on the result of the validation phase obtained, it can be examined that the standard error prediction (SEP) generated is 1,33. Standard error validation is not good because the value exceeds one (1). The validation Fig. of $\mathrm{L}^{*}$ is presented on Fig. 11. The combination of calibration and validation of $\mathrm{L}^{*}$ is presented on Fig. 12.

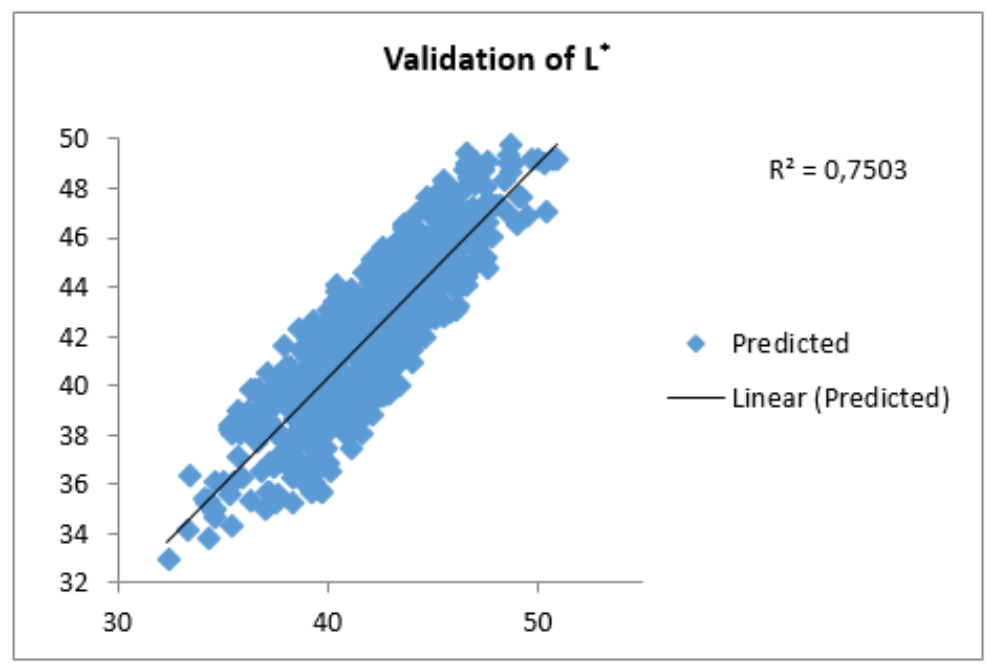

Fig. 11. Validation of $\mathrm{L}^{*}$ on Ridge Gourd 


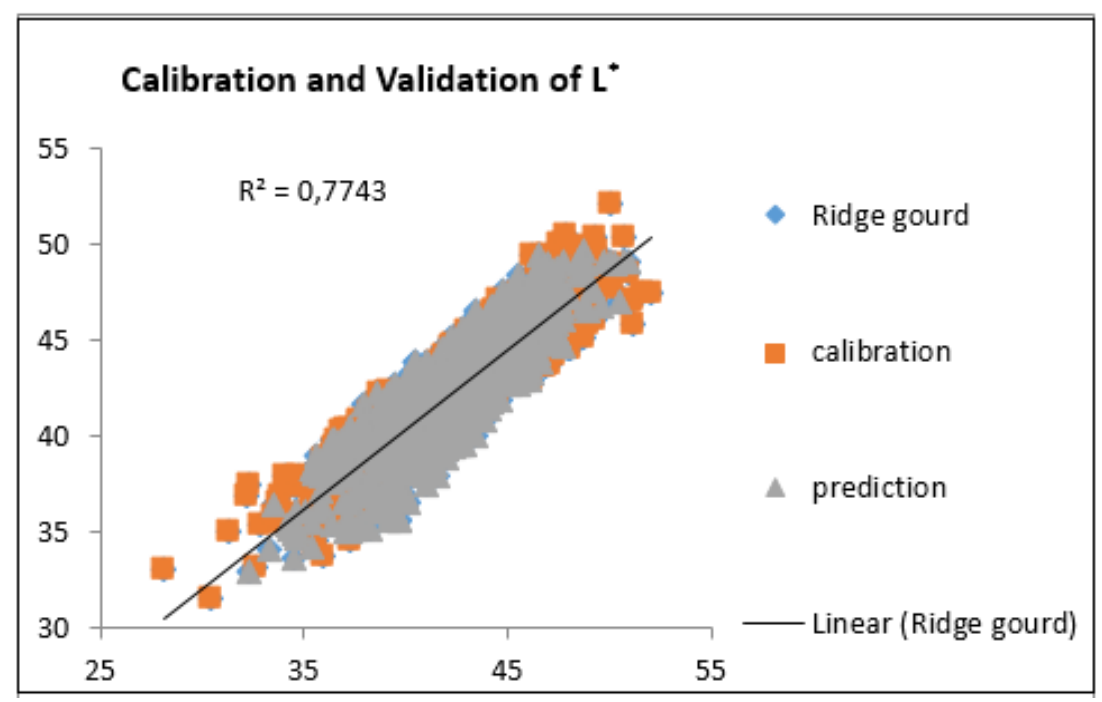

Fig. 12. Calibration and Validation of $\mathrm{L}^{*}$ on Ridge Gourd

\section{I. $a^{*}$ Value}

At calibration phase the assessment of $\mathrm{a}^{*}$ used 627 samples of reflectant data and 600 samples for validation phase with wavelength $312-1050 \mathrm{~nm}$. The calibration Fig. of $\mathrm{a}^{*}$ is presented on Fig. 13.

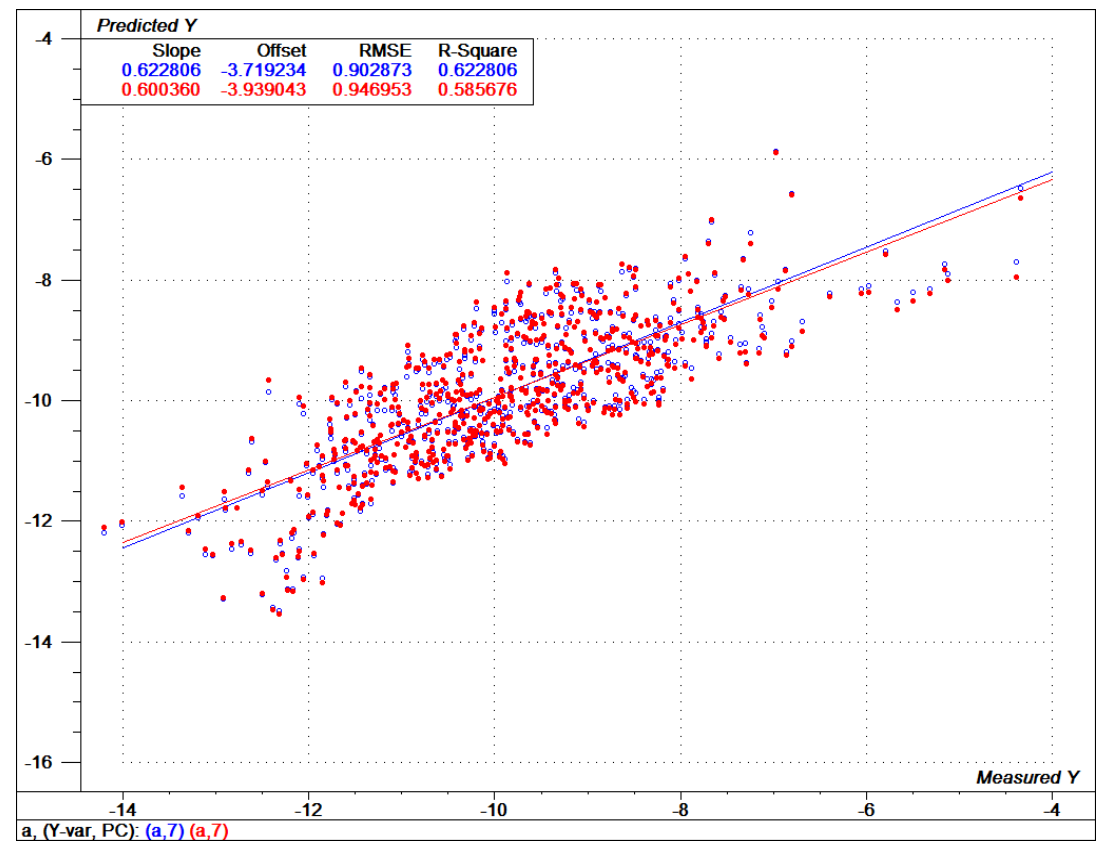

Fig. 13. Calibration of $\mathrm{a}^{*}$ on Ridge Gourd

At calibration phase, the standard error of calibration (SEC) is 0,90 . Considering the standard error values at the calibration phase, it can be assumed that the calibration regression that has been built is acceptable due to the default error value close to zero (0). To analyze the accuracy of regression equation of calibration it is necessary to perform the validation phase.

The validation phase of $\mathrm{a}^{*}$ assessment of ridge gourd fruit used different samples from calibration which 600 samples from NIR absorbance data and destructive method mesurement. The level of accuracy in the validation phase based on the form and model of calibration largely determined by the standard error of prediction (SEP). Based on the result of the validation phase obtained, it can be examined that the standard error prediction (SEP) generated is 1,12. Standard error validation is not good because the value exceeds one (1). The validation Fig. of $\mathrm{a}^{*}$ is presented on Fig. 14. The combination of calibration and validation of $\mathrm{a}^{*}$ is presented on Fig. 15. 


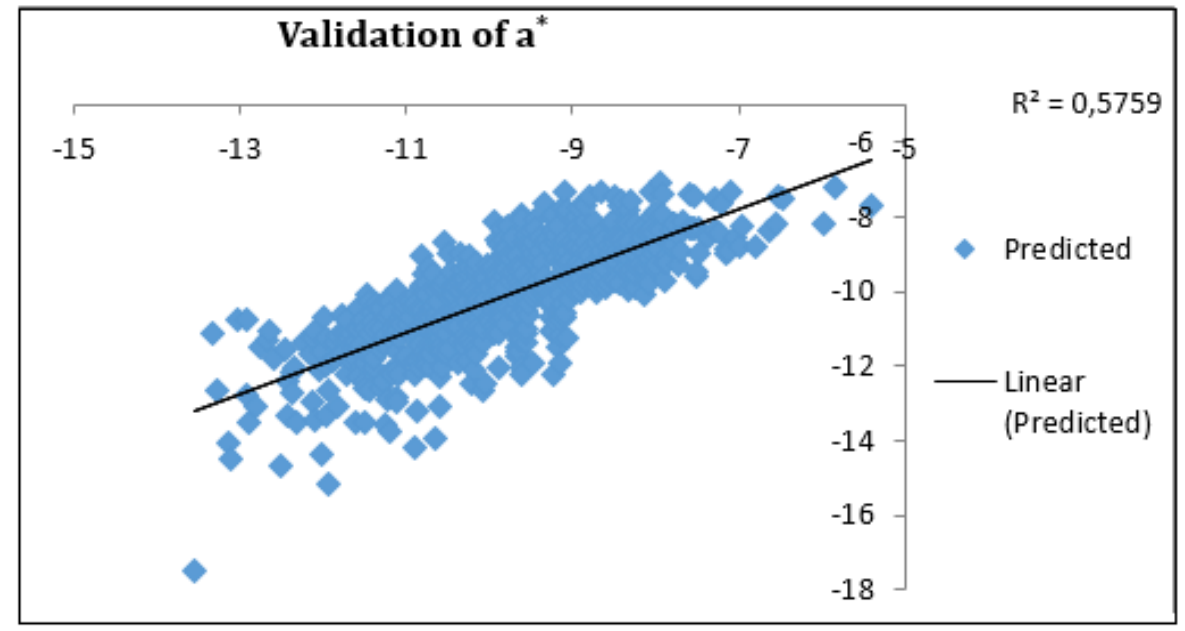

Fig. 14. Validation of $\mathrm{a}^{*}$ on Ridge Gourd

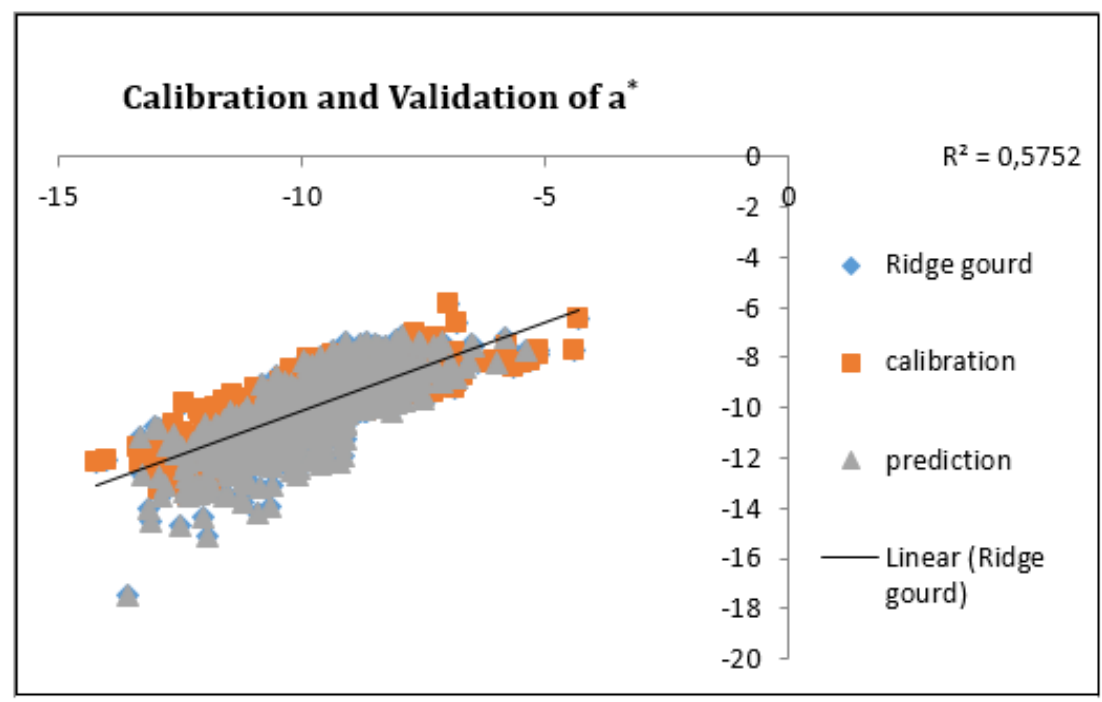

Fig. 15. Calibration and Validation of $\mathrm{a}^{*}$ on Ridge Gourd

\section{J. $b^{*}$ Value}

At calibration phase the assessment of $b^{*}$ used 600 samples of reflectant data and 608 samples for validation phase with wavelength 312- $1050 \mathrm{~nm}$. The calibration Fig. of $\mathrm{b}^{*}$ is presented on Fig. 16.

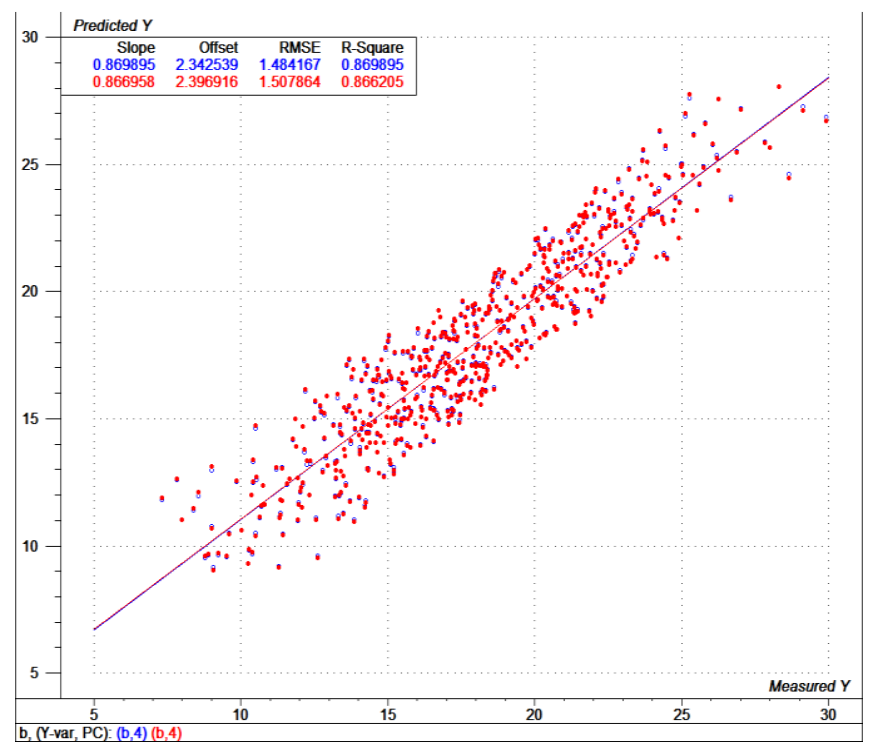

Fig. 16. Calibration of $b^{*}$ on Ridge Gourd 
At calibration phase, the standard error of calibration (SEC) is 1,48. Considering the standard error values at the calibration phase, it can be assumed that the calibration regression that has been built is not good due to the default error value exceeds one (1). To analyze the accuracy of regression equation of calibration it is necessary to perform the validation phase.

The validation phase of $\mathrm{b}^{*}$ assessment of ridge gourd fruit used different samples from calibration which 608 samples from NIR absorbance data and destructive method mesurement. The level of accuracy in the validation phase based on the form and model of calibration largely determined by the standard error of prediction (SEP). Based on the result of the validation phase obtained, it can be examined that the standard error prediction (SEP) generated is 1,55. Standard error validation is not good because the value exceeds one (1). The validation Fig. of $b^{*}$ is presented on Fig. 17. The combination of calibration and validation of $b^{*}$ is presented on Fig. 18.

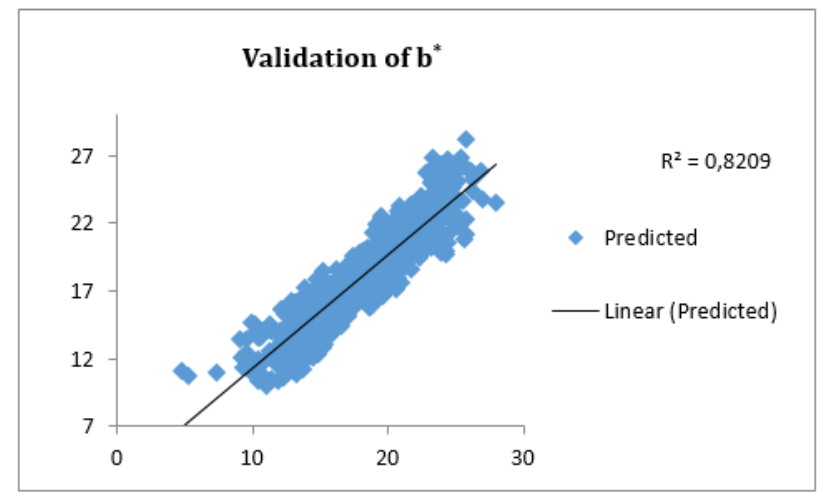

Fig. 17. Validation of $b^{*}$ on Ridge Gourd

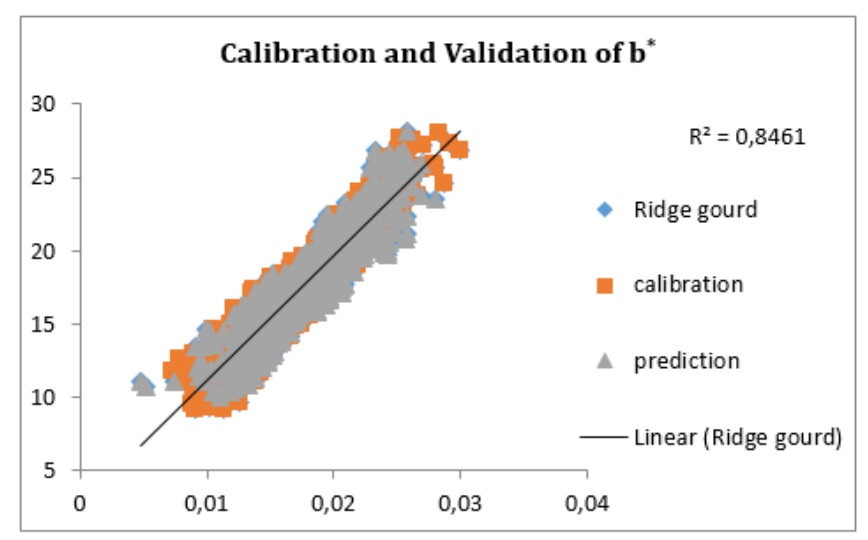

K. Hue Value

Fig. 18. Calibration and Validation of $b^{*}$ on Ridge Gourd

At calibration phase the assessment of hue ${ }^{0}$ used 615 samples of reflectant data and 618 samples for validation phase with wavelength 312- $1050 \mathrm{~nm}$. The calibration Fig. of hue ${ }^{0}$ is presented on Fig. 19.

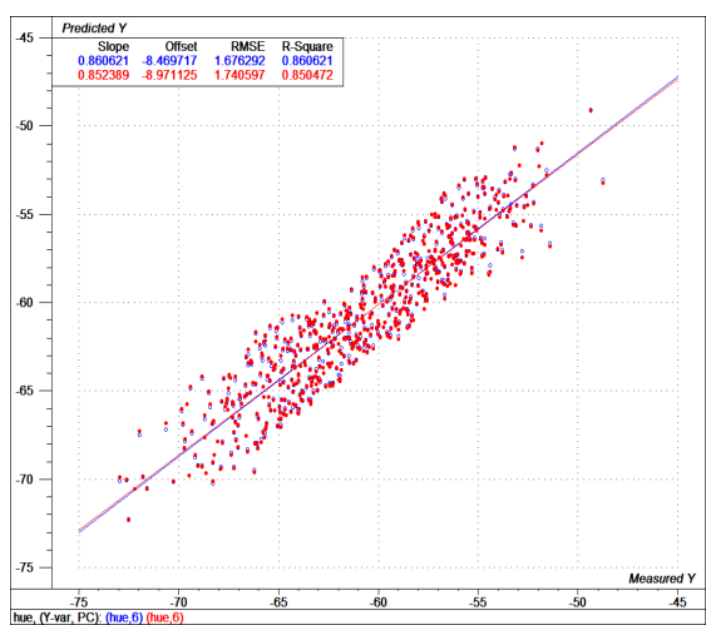

Fig. 19. Calibration of $\mathrm{Hue}^{0}$ on Ridge Gourd 
At calibration phase, the standard error of calibration (SEC) is 1,67. Considering the standard error values at the calibration phase, it can be assumed that the calibration regression that has been built is not good due to the default error value exceeds one (1). To analyze the accuracy of regression equation of calibration it is necessary to perform the validation phase.

The validation phase of hue $\mathrm{e}^{0}$ assessment of ridge gourd fruit used different samples from calibration which 618 samples from NIR absorbance data and destructive method mesurement. The level of accuracy in the validation phase based on the form and model of calibration largely determined by the standard error of prediction (SEP). Based on the result of the validation phase obtained, it can be examined that the standard error prediction (SEP) generated is 1,38. Standard error validation is not good because the value exceeds one (1). The validation Fig. of hue $^{0}$ is presented on Fig. 20. The combination of calibration and validation of hue ${ }^{0}$ is presented on Fig. 21.

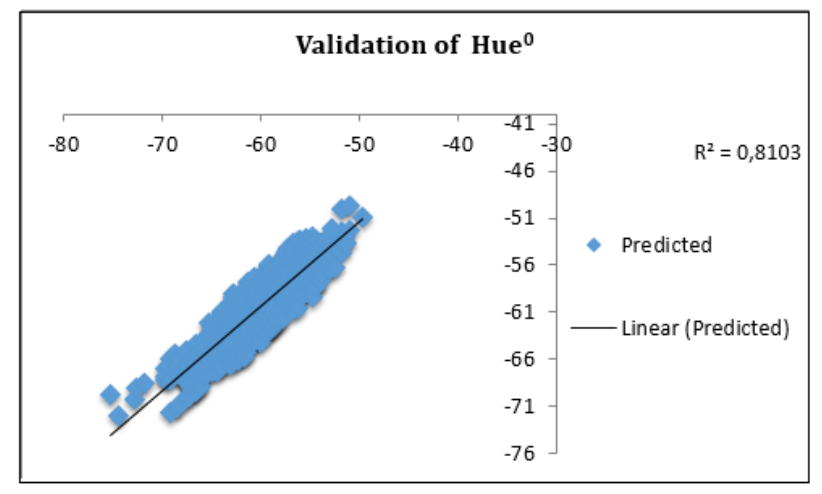

Fig. 20. Validation of Hue ${ }^{0}$

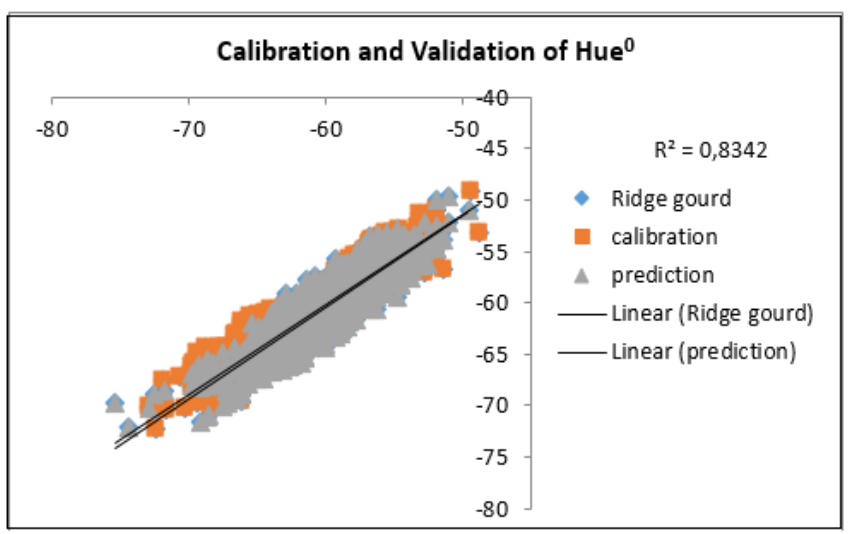

Fig. 21. Calibration and Validation of $\mathrm{Hue}^{0}$

\section{Chroma value}

At calibration phase the assessment of chroma used 627 samples of reflectant data and 620 samples for validation phase with wavelength $312-1050 \mathrm{~nm}$. The calibration Fig. of hue ${ }^{0}$ is presented on Fig. 22.

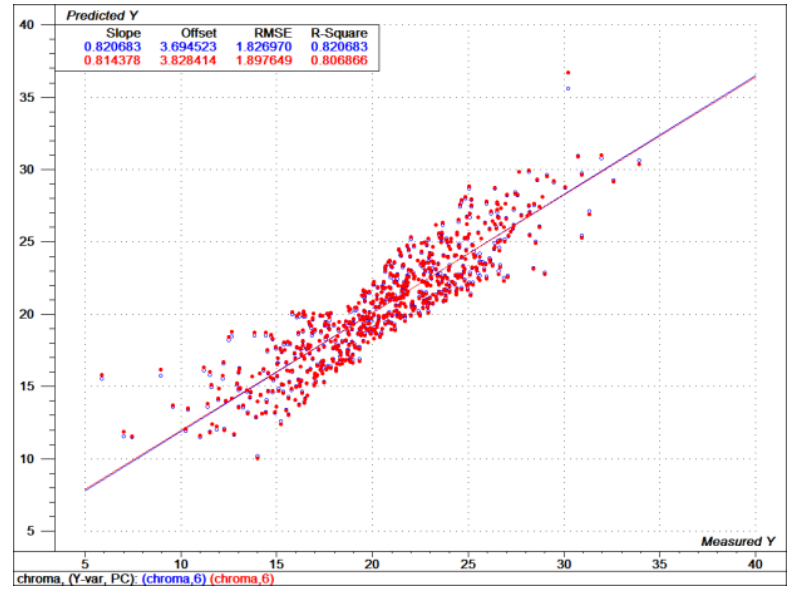

Fig. 22. Calibration of Chroma 
At calibration phase, the standard error of calibration (SEC) is 1,827 . Considering the standard error values at the calibration phase, it can be assumed that the calibration regression that has been built is not good due to the default error value exceeds one (1). To analyze the accuracy of regression equation of calibration it is necessary to perform the validation phase.

The validation phase of chroma assessment of ridge gourd fruit used different samples from calibration which 620 samples from NIR absorbance data and destructive method mesurement. The level of accuracy in the validation phase based on the form and model of calibration largely determined by the standard error of prediction (SEP). Based on the result of the validation phase obtained, it can be examined that the standard error prediction (SEP) generated is 1,73. Standard error validation is not good because the value exceeds one (1). The validation Fig. of chroma is presented on Fig. 23. The combination of calibration and validation of chroma is presented on Fig. 24.

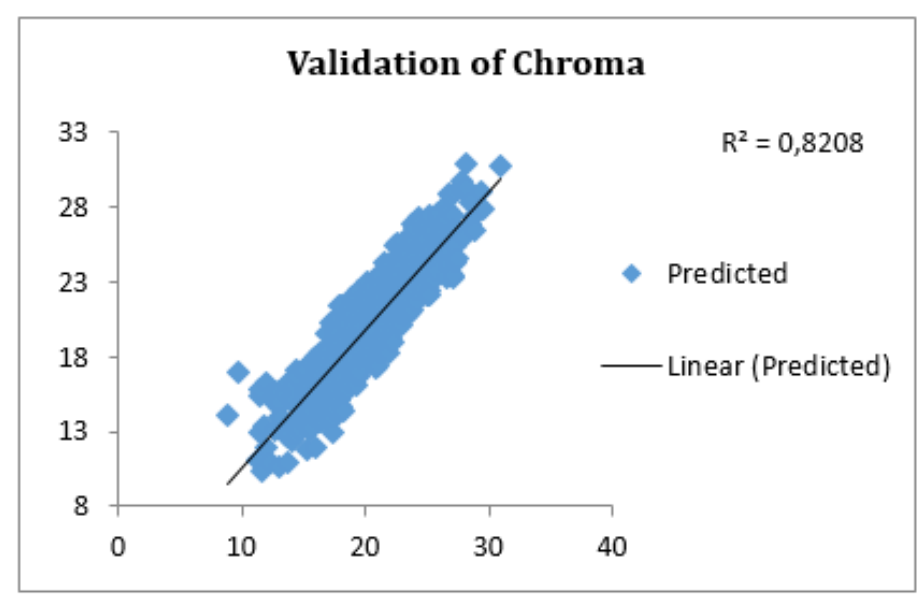

Fig. 23. Validation of Chroma

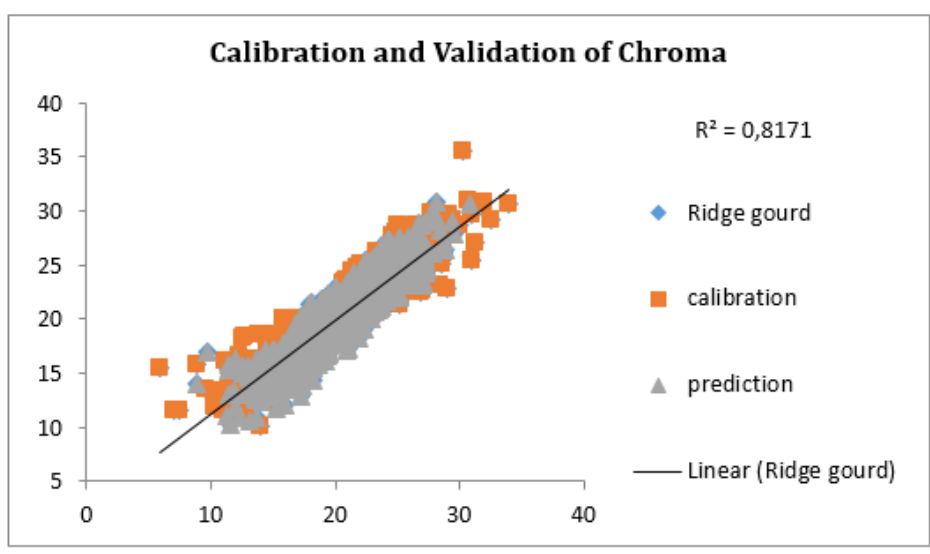

Fig. 24. Calibration and Validation of Chroma

\section{CONCLUSION}

Detection of ridge gourd was able to measure dissolved solids, moisture content, firmness and color values during storage using near-infrared spectrometer.

\section{REFERENCES}

[1] Blanco, M., Villarroya, I., 2002. NIR spectroscopy: a rapid-response analytical tool. Trends Anal. Chem. 21, 240-250.

[2] Bobelyn, E., Serban, A., Nicu, M., Lammertyn, J., Nicolaï, B.M., Saeys, W., 2010. Postharvest quality of apple predicted by NIR-spectroscopy: study of the effect of biological variability on spectra and model performance. Postharvest Biol. Technol. 55, 133-143.

[3] Chen, J.Y., Zhang, H., Matsunaga, R., 2006. Rapid determination of the main organic acid composition of raw Japanese apricot fruit juices using near-infrared spectroscopy. J. Agric. Food Chem. 54, 9652-9657.

[4] Gómez, A.H., He, Y., Pereira, G., 2006. Non-destructive measurement of acidity, soluble solids and firmness of Satsuma mandarin using Vis/NIR-spectroscopy techniques. J. Food Eng. 77, 313-319.

[5] Kawano, S., 1998. New application of nondestructive methods for quality evaluation of fruit and vegetables in Japan. J. Jpn. Soc. Horticult. Sci. 67, 1176-1179. 
[6] Kusumiyati, T. Akinaga, S. Yonemori, T. Shikanai, H. Okamoto, T. Tanabe, S. Kawasaki. 2008. Internal quality sensor of fruit jagged surface: preliminary study of bitter gourd (Momordica charantia Linn). Acta Horticulturae Vol.768 p.391-398.

[7] Kusumiyati, T. Akinaga, S. Yonemori, S. Kawasaki, T. Tanabe. 2007. Evaluation of Tomato Quality on Tree and after Harvesting using portable NIR Spectroscopy. Journal of the society of agricultural structures, Japan (Nogyo Shisetsu) Vol 38 No.2 pp.117-126

[8] Kusumiyati, T. Akinaga, M. Tanaka, S. Kawasaki. On tree and after harvesting evaluation of firmness, color, and lycopene content of tomato fruit using portable NIR spectroscopy. 2008. Journal of food, agriculture and environment Vol.6 No.2 pp.132-137.

[9] Liu, Y., Ying, Y., 2005. Use of FT-NIR spectrometry in non-invasive measurements of internal quality of 'Fuji' apples. Postharvest Biol. Technol. 37, 65-71.

[10] Liu, Y., Ying, A., Fu, X., Lu, H., 2007. Experiments on predicting sugar content in apples by FT-NIR Technique. J. Food Eng. 80, 986-989.

[11] McGlone, V.A., Jordan, R.B., Martinsen, P.J., 2002. Vis/NIR estimation at harvest of pre- and post-storage quality indices for 'Royal Gala' apple. Postharvest Biol. Technol. 25, 135-144.

[12] Nicolaï, B.M., Beullens, K., Bobelyn, E., Peirs, A., Saeys, W., Theron, K.I., Lammertyna, J., 2007. Nondestructive measurement of fruit and vegetable quality by means of NIR spectroscopy: a review. Postharvest Biol. Technol. 46, 99-118.

[13] Ranganna, S., 2008. Handbook of Analysis and Quality Control for Fruit and Vegetable Products. McGraw-Hill Publishing Company Limited, New Delhi, pp. 444.

[14] Saranwong, S., Sornsrivichai, J., Kawano, S., 2004. Prediction of ripe-stage eating quality of mango fruit from its harvest quality measured nondestructively by near infrared spectroscopy. Postharvest Biol. Technol. 31, 137-145.

[15] Slaughter, D.C., Thompson, J.F., Tan, E.F., 2003. Nondestructive determination of total soluble solids in fresh prune using near infrared spectroscopy. Postharvest Biol. Technol. 28, 437-444.

[16] Sun, T., Huang, K., Xu, H., Ying, Y., 2010. Research advances in nondestructive determination of internal quality in watermelon/melon: a review. J. Food Eng. 100, 569-577.

[17] Varoquaux, P., Sani Ozdemir, I., 2005. Packaging and produce degradation. In: Lamikanra, O., Imam, S., Ukuku, D. (Eds.), Produce Degradation: Pathways and Prevention. CRC Press, pp. 117-153.

[18] Wang, J., Nakano, K., Ohashi, S., 2011a. Nondestructive evaluation of jujube quality by visible and near-infrared spectroscopy. LWT-Food Sci. Technol. 44, 1119-1125.

[19] Wang, J., Nakano, K., Ohashi, S., 2011b. Nondestructive detection of internal insect infestation in jujubes using visible and near-infrared spectroscopy. Postharvest Biol. Technol. 59, 272-279. 